\title{
URGENSI PENERAPAN MUATAN LOKAL BATIK PADA SISWA TUNA RUNGU WICARA
}

\author{
Inayatul Ulya \\ Pendidikan Bahasa Inggris \\ Fakultas Keguruan dan Ilmu Pendidikan Universitas Pekalongan \\ Korespondensi: inayasetyobudi@yahoo.com
}

\begin{abstract}
SMALB PRI Pekalongan (Senior High School for Special Need Students) implements Javanese local content to hearing impairment students. As it is known that hearing impairments students have limitation to hear and to communicate, so it is needed to be investigated whether the implementation of the local content is suitable for them or not. This research was aimed to: 1) identify the problems faced by the teacher in implementing Javanese local content to hearing impairment students, 2) describe the urgency of implementing batik local content to hearing impairment students. The researcher used descriptive qualitative research design. Data collection was done by conducting interview and distributing questionnaire to the headmaster, Javanese local content teacher and the students. The result of the research showed that: 1) Javanese local content teacher faced some problems in teaching learning process since there was no Javanese local content book for students with hearing impairment. In addition, the limitation to hear and speak made them rarely use Javanese vocabularies to communicate. 2) Batik local content was very urgent to be implemented considering the school location which is in Pekalongan with batik as one of local content. Therefore, it can be concluded that the implementation of Javanese local content was not appropriate for hearing impairment students. Meanwhile, Batik Local Content can be one of alternative local content to be implemented. By implementing it, it is hoped that after they have graduated, they have skill to produce batik and it can support their income. Certainly, its application needs to be supported by Pekalongan government through providing facilities, such as Batik workshop and its equipments, also batik gallery to market their product.
\end{abstract}

Keyword: Urgency, Batik, Local Content.

\begin{abstract}
ABSTRAK
SMALB PRI Pekalongan (Sekolah Menengah Atas Luar Biasa Persatuan Rakyat Indonesia) menerapkan muatan lokal Bahasa Jawa pada siswa tuna rungu wicara. Sebagaimana diketahui bahwa Siswa tuna rungu wicara mempunyai keterbatasan dalam mendengar dan berkomunikasi, sehingga perlu diteliti apakah penerapan muatan lokal tersebut sesuai untuk mereka. Penelitian ini bertujuan untuk: 1) mengidentifikasi permasalahan-permasalahan pada penerapan muatan lokal Bahasa Jawa pada siswa Tuna Rungu Wicara, 2) mendeskripsikan urgensi penerapan muatan lokal Batik pada siswa Tuna rungu wicara. Peneliti menggunakan desain deskriptif kualitatif. Pengumpulan data dilakukan dengan wawancara dan memberikan angket kepada kepala sekolah, guru muatan lokal Bahasa Jawa, dan siswa tuna rungu wicara. Hasil penelitian ini menunjukkan: 1) guru muatan lokal Bahasa Jawa menghadapi permasalahan dalam proses belajar mengajar dikerenakan tidak tersedianya buku muatan Lokal Bahasa Jawa yang dibuat khusus untuk anak tuna rungu wicara. Selain itu, keterbatasan pendengaran dan tidak mampu berbicara menjadikan siswa sangat terbatas untuk menggunakan kosa kata Bahasa Jawa, 2) muatan Lokal Batik sangat penting untuk diterapkan dengan pertimbangan bahwa lokasi sekolah berada di Kota Pekalongan dengan batik sebagai salah satu kearifan lokal. Selain itu, keterampilan siswa tuna rungu wicara perlu untuk dikembangkan. Dengan demikian dapat disimpulkan bahwa penerapan muatan Bahasa Jawa kurang tepat diberikan kepada siswa tunarungu wicara, sedangkan muatan lokal batik dapat dijadikan salah satu pilihan untuk diterapkan. Dengan diterapkannya muatan lokal batik, diharapkan pada saat siswa lulus, mereka memiliki ketrampilan membatik dan dapat dijadikan sumber perekonomian mereka. Tentunya penerapan muatan lokal batik perlu adanya dukungan dari pemerintah kota Pekalongan dengan disedikannya fasilitas berupa ruang workshop batik dan peralatan proses pembuatan batik serta galeri batik untuk memasarkan batik hasil buatan mereka.
\end{abstract}

Kata Kunci: Urgensi, Batik, Muatan lokal 


\section{PENDAHULUAN}

Pendidikan khusus merupakan upaya dalam memenuhi pendidikan bagi anak anak berkebutuhan khusus. Pendidikan ini dirancang secara khusus, dijalankan secara teratur, serta dinilai keefektifannya untuk membantu siswa berkebutuhan khusus dalam mencapai tahap kemandirian dan keberhasilan hidup Pada pengelolaan pendidikan khusus diperlukan kurikulum yang sesuai dengan kemampuan peserta didik.

Menurut Dakir (2004) kurikulum ialah suatu program pendidikan yang berisikan berbagai bahan ajar dan pengalaman belajar yang diprogramkan, direncanakan dan dirancangkan secara sistematik atas dasar norma-norma yang berlaku yang dijadikan pedoman dalam proses pembelajaran bagi tenaga kependidikan dan peserta didik untuk mencapai tujuan pendidikan.

Puskur (2002) mendefinisikan KTSP sebagai kurikulum operasional dilaksanakan dan disusun oleh masing-masing satuan pendidikan. Salah satu prinsip pengembangan KTSP diantaranya kurikulum dikembangkan berdasarkan prinsip-prinsip yang terpusat pada potensi, perkembangan, kebutuhan, dan kepentingan peserta didik dan lingkunganya. Dengan demikian, SMALB PRI telah menerapkan kurikulum yang disesuaikan dengan kemampuan peserta didik. Salah satu bagian dari penerapan KTSP tersebut adalah diterapkannya muatan lokal.

Pusat Kurikulum (2007: 2), mengemukakan bahwa muatan lokal bertujuan untuk memberikan bekal pengetahuan, ketrampilan, dan perilaku kepada peserta didik agar mereka memiliki wawasan yang mantap tentang keadaan lingkungan dan kebutuhan masyarakat sesuai nilai-nilai/ aturan yang berlaku didaerahnya dan mendukung kelangsungan pembangunan daerah serta pembangunan nasional.

Dasar dari pelaksanaan kurikulum muatan lokal (Pusat kurikulum, 2007) sebagai berikut ini:

1. Undang-undang Dasar Negara Republik Indonesia Tahun 1945 Pasal 31.

2. Undang-Undang republic Indonesia Nomor 32 Tahun 2004 tentang Pemerinatahan Daerah Pasal 13 ayat 1 (f),

3. Undang-Undang Republik Indonesia Nomor 20 Tahun 2003 tantang Sistem Pendidikan Nasional Pasal 37 ayat 91) dan pasal 38 ayat (2).

4. Peraturan Pemerintah Republik Indonesia Nomor 19 tahun 2005 tentang Standar Nasional Pendidikan.

5. Peraturan Menteri Pendidikan Nasional nomor 22 Tahun 2006 tentang Standar Isi untuk Satuan Pendidikan Dasar dan Menengah.

6. Peraturan Menteri Pendidikan Nasional Nomor 23 Tahun 2006 tentang Standar Kompetensi Lulusan.

Dengan demikian dapat disimpulkan bahwa pada penerapan kurikulum KTSP di SMALB, perlu adanya muatan lokal. Muatan lokal diberikan sesuai dengan kearifan lokal yang dimiliki oleh suatu daerah dengan tujuan agar siswa memiliki pengetahuan, keterampilan dan mampu menrapkannya dalam kehidupan sehari hari.

Berdasarkan posisi geografis, SMALB PRI terletak di Kota Pekalongan Jawa Tengah. Oleh karena itu, SMALB PRI menerapkan muatan lokal Bahasa Jawa. Penetapan Bahasa Jawa sebagai salah satu mata pelajaran muatan lokal (Mulok) dilakukan berdasarkan Keputusan Gubernur Jawa Tengah Nomor. 895.5/01/2005 tentang 
Kurikulum Mata Pelajaran Bahasa Jawa untuk Jenjang Pendidikan SD/SDLB/MI, SMP/SMPLB/MTs, dan SMA/SMALB/SMK/MA Negeri dan Swasta Propinsi Jawa Tengah (Pemprov Jateng, 2005). Pembelajaran Bahasa Jawa berfungsi untuk memperkenalkan siswa mengenal dirinya dan budaya daerahnya. Hal ini dikarenakan bahwa dalam kurikulum pembelajaran bahasa, materi dikembangkan dengan tujuan untuk mempersiapkan peserta didik untuk menguasai kompetensi yang menjadikan mereka mampu merefleksikan pengalamannya sendiri dan pengalaman orang lain, mengungkapkan gagasan dan perasaan, dan memahami beragam nuansa makna dalam bahasa yang diajarkan (Depdiknas, 2004: 5).

SMALB PRI menerapkan muatan Bahasa Jawa pada semua ketunaan, termasuk pada siswa tuna rungu wicara. Tuna rungu adalah seseorang atau individu yang mengalami kekurangan atau kehilangan kemampuan mendengar, baik sebagian atau seluruhnya yang diakibatkan oleh tidak berfungsinya sebagian atau seluruh indera pendengaran (TIM FIP UPI: 2007). Sedangkan Tuna wicara merupakan gangguan verbal pada seseorang sehingga mengalami kesulitan dalam berkomunikasi melalui suara. Sebagian tunawicara adalah mereka yang menderita tuna rungu sejak bayi ataupun lahir, yang karenanya tidak dapat menangkap pembicaraan orang lain, sehingga tak mampu mengembangkan kemampuan bicaranya meskipun tak mengalami gangguan pada alat suaranya (Sadjaah, 2005). Penyandang tuna rungu wicara adalah anak yang kehilangan kemampuan untuk mendengar baik sebagian maupun seluruhnya yang mengakibatkan tidak mampu untuk menggunakan alat pendengarannya dalam kehidupan sehari-hari dan juga tidak mampu mengembangkan kemampuan bicaranya (Jannah dan Kartika, 2014: 3).

Sebagaimana diketahui, bahwa siswa tuna rungu mempunyai keterbatasan dalam pendengaran dan berkomunikasi secara lisan, sehingga dalam penerpan muatan lokal bahasa Jawa, permasalahan bisa muncul. Oleh karena itu, peneliti memfokuskan pada penerapan muatan lokal Bahasa jawa dan permasalahan apa saja yang dihadapi dalam melaksanakan muatan lokal tersebut. Selain itu, perlu diidentifikasi apakah diperlukan muatan lokal tambahan yang disesuakan dengan minat siswa dan kearifan lokal dimana siswa tuna rungu wicara belajar, yaitu muatan lokal yang mengangkat budaya Pekalongan-Batik. Penelitian ini bertujuan untuk:

1. mengidentifikasi permasalahan yang dihadapi pada penerapan muatan lokal siswa Tuna Rungu Wicara.

2. mendeskripsikan urgensi penerapan muatan lokal Batik pada siswa Tuna rungu wicara.

\section{METODE}

Peneliti menggunakan desain deskriptif kualitatif. Menurut Bungin (2007: 68) penelitian deskriptive kualitatif bertujuan untuk menggambarkan, meringkaskan berbagai kondisi, berbagai situasi, atau berbagai fenomena realitas sosial yang ada di masyarakat yang menjadi objek penelitian, dan berupaya menarik realitas itu ke permukaan sebagai suatu cirri, karakter, sifat, model, tanda, atau gambaran tentang kondisi, situasi, ataupun fenomena tertentu. Penelitian dilakukan di SMALB PRI Kota Pekalongan.

Pada proses pengumpulan data, menurut Yusuf (2014: 199), apabila peneliti langsung ke lapangan (field), maka ia dapat menggunakan berbagai teknik seperti kuesioner, wawancara, observasi, telepon surevei, dan tes. Pada penelitian ini, peneliti 
melakukan wawancara dan sebar kuesioner kepada kepala sekolah, guru muatan lokal, dan siswa tuna rungu wicara.

Langah berikutnya setelah data terkumpul adalah peneliti melakukan analisis data dengan menggunakan model Miles dan Huberman. Menurut Yusuf (2014: 407) model Miles dan Huberman meliputi tahapan: reduksi data data reduction: 2) data display (display data), dan 3) penarikan kesimpulan.. Kerangka pikir dari penelitian ini dapat dilihat pada bagan berikut:

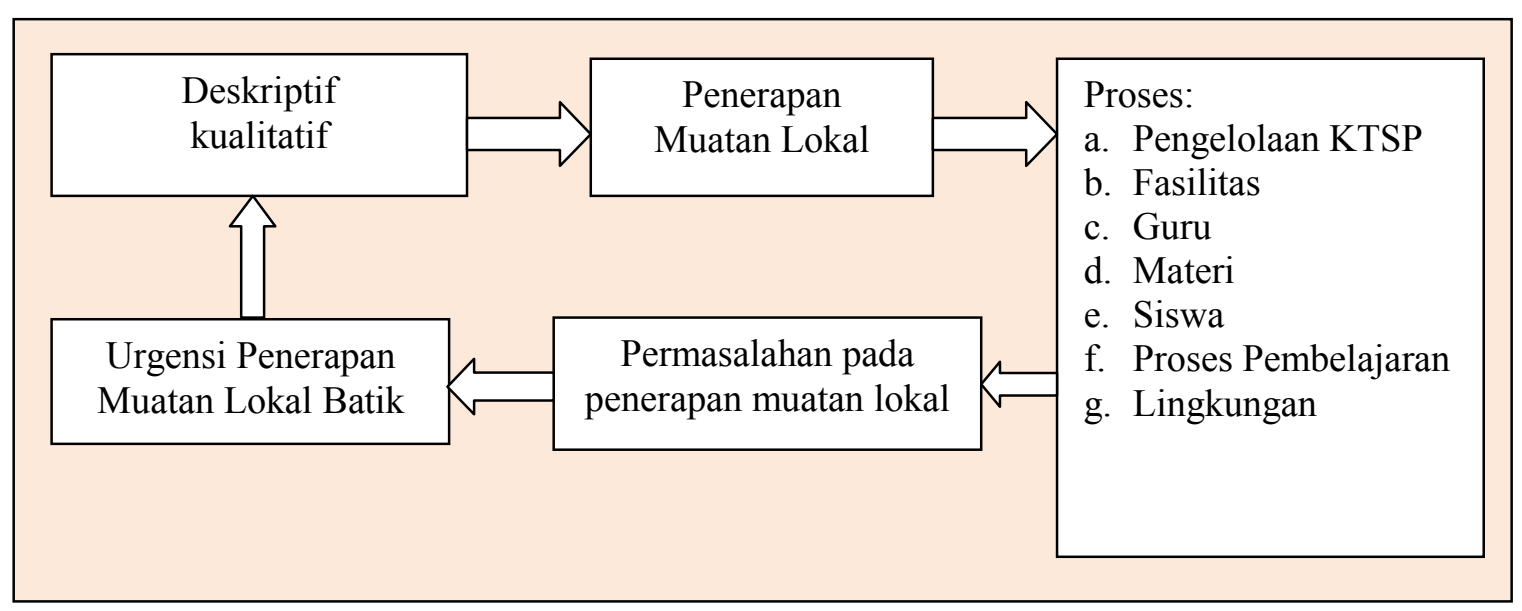

Gambar 1. Alur penelitian

\section{HASIL DAN PEMBAHASAN}

\subsection{Permasalahan pada Penerapan Muatan Lokal}

Sebelum mengidentifikasi permasalahan yang dihadapi oleh guru pada proses pembelajaran muatan lokal, terlebih dahulu peneliti menganalisis pengelolaan kurikulum KTSP melalui dokumen KTSP di SMALB PRI.

\subsubsection{Organisasi dan Manajemen (Pengelolaan KTSP)}

\section{Organisasi KTSP}

SMALB PRI memiliki tim KTSP yang dibentuk oleh kepala sekolah dengan SK no 988.1/A.003/III/2012 yang terdiri dari unsur sekolah, komite sekolah, pengawas, wali siswa, dan tokoh masyarakat. Adanya tim ini bertujuan untuk menyusun dokumen KTSP yang terdiri dari buku 1 yang berisi tentang visi misi, jatidiri sekolah, struktur kurikulum, prota, promes; sedangkan buku 2 berisi silabus, dan buku 3 berisi tentang RPP. Keberadaan Tim ini telah ada sebagian dan berfungsi, sebagian bukti implementasi masih dalam skala kecil, dan sebagian besar masih perencanaan.

2. Manajemen KTSP

Manajemen ini memiliki konsideran seperti dokumen KTSP, program kerja dan jadwal meninjau muatan lokal, evaluasi mulok, dan pertemuan tim KTSP untuk membahas mulok. Dokumen KTSP yang meliputi SI dan SKL mulok telah disusun dengan bukti tertulis dan terorgansir dengan baik, sedangkan silabus mulok telah disusun meskipun baru sebagian kecil. Sementara perangkat penilaian dan laporan hasil belajar telah terorganisasi dan terstruktur dengan baik.

Dari manajerial pelaksanaan seperti program kerja, evaluasi pelaksanaan mulok, dan pertemuan tim KTSP untuk membahas mulok telah dilaksanakan meskipun sebagian besar masih dalam perencanaan. 


\subsubsection{Ketenagaan pengajaran muatan lokal}

Ketenagaan yang dimaksud dalam komponen ini adalah ketersediaan guru dalam program mulok. SMALB PRI memiliki komitmen untuk mengembangkan kapasitas dari tenaga pengajarnya khususnya untuk muatan lokal

Mulok sebagai pengembangan struktur kurikulum yang menjadi penciri sekolah mempersyaratkan kesesuaian dengan latar belakang akademik. SMALB PRI memiliki 1 guru mulok yang sesuai dengan kualifikasi yaitu guru mulok Bahasa Jawa.

\subsubsection{Fasilitas}

SMALB PRI memiliki fasilitas yang sangat memadai, fasilitas tersebut meliputi:
1) Pendopo
2) Ruang kelas
3) Ruang praktikum komputer
4) Ruang kepala sekolah
5) Ruang tata usaha
6) Mushola
7) Kantin
8) Perpustakaan

Fasilitas tersebut sudah terpenuhi dengan baik, namun membutuhkan perwatan yang lebih baik agar sarana prasarana yang tersedia tetap dapat

3.1.4. Kesiswaan dimanfaatkan fungsinya dengan maksimal pada proses belajar mengajar.

Data siswa kelas X, XI, dan XII berjumlah 22 orang dengan sebaran, kelas X sebanyak 5, kelas XI sebanyak 8, dan kelas XII sebanyak 9 orang. Jumlah ini relatif sedikit karena jumlah anak berkebutuhan khusus di Kota Pekalongan yang melanjutkan pendidikan sampai dengan jenjang SMALB relatif sedikit.

\subsubsection{Permasalahan dalam penerapan muatan lokal Bahasa Jawa}

SMALB PRI menerapkan muatan lokal Bahasa Jawa, dalam proses penerpannya ditemukan permasalahan-permasalahan yang dihadapi guru.

Tabel 1 Proses Pelaksanan Muatan Lokal Bahasa Jawa

\begin{tabular}{c|l|c|c|c|c|c}
\multirow{2}{*}{ No } & \multicolumn{1}{|c|}{ Komponen } & \multicolumn{5}{c}{ Skala } \\
\cline { 3 - 7 } & & $\mathbf{5}$ & $\mathbf{4}$ & $\mathbf{3}$ & $\mathbf{2}$ & $\mathbf{1}$ \\
\hline 1 & Silabus \& RPP & & $\sqrt{ }$ & & & \\
\hline 2 & Buku Ajar/ Materi & & & & $\sqrt{ }$ & \\
\hline 3 & Proses Pembelajaran & & & & $\sqrt{ }$ & \\
\hline 4 & Media Pembelajaran & & & & $\sqrt{ }$ &
\end{tabular}

Keterangan:

$1=$ tidak baik

$2=$ cukup

$3=$ netral

$4=$ baik

$5=$ sangat baik

Berdasarkan angket dan wawancara dengan guru muatan lokal dapat diketahui bahwa silabus dan RPP disusun oleh guru muatan lokal Bahasa Jawa, semua komponen dalam Silabus dan RPP disusun sesuai dengan 
standar penyusunan. Guru muatan lokal Bahasa Jawa merupakan lulusan prodi Bahasa Jawa sehingga dapat menysun perangkat pembelajaran dengan baik.

Sedangkan pada buku ajar, guru kesulitan untuk menemukan buku ajar Bahasa Jawa yang diperuntukkan khusus siswa tuna rungu wicara. Tidak adanya buku ajar untuk siswa tuna rungu wicara tersebut menjadikan proses pembelajaran terhambat, sehingga guru mensiasati dengan menggunakan buka Bahasa Jawa sekolah SMP dengan tingakatan materi yang disederhankan. Materi yang diajarkan adalah materi yang berkaitan dengan kehidupan sehari-hari.

Permasalahan lain yang muncul adalah pada proses belajar mengajar. Dengan latar belakang mereka yang tidak mampu mendengar dan berbicara, pembelajaran Bahasa jawa terbatas pada penulisan kosa kata bahasa jawa. Sedangkan pada pengucapan kosa kata bahasa jawa, siswa megucapkan sesuai kemampuan mereka atau dengan membaca gerak bibir. Proses pembelajaran pada siswa tuna rungu wicara membutuhkan tehnik khusus agar dapat dengan mudah dipahami oleh siswa, yaitu dengan bantuan bahasa isyarat, gerak bibir, mimik wajah.

Selain materi dan proses penyampaian materi, media khusus untuk muatan lokal Bahasa Jawa belum tersedia dengan baik. Guru hanya menggunakan barang-barnag disekitar untuk menerangkan kosa kata.

Dengan adanya permasahan pada proses pembelajaran, pencapaian siswa tuna rungu wicara untuk menguasai Bahasa Jawa tidak maksimal. Selain itu, lingkungan Kota Pekalongan yang berada dipesisir pantai utara cenderung tidak dapat menggunakan Bahasa Jawa kromo inggil. Kondisi lingkungan sangat mempengaruhi kemampuan siswa.

Berdasarkan permasalahan tersebut, peneliti selanjutnya melakukan wawancara kepada pihak sekolah terkait urgensi penerpan muatan lokal Batik dengan pertimbangan bahwa siswa SMALB PRI berasal dari Pekalongan dengan lingkungan masyarakat yang memproduksi batik.

\subsection{Urgensi Penerapan Muatan Lokal Batik untuk Siswa Tuna Rungu Wicara}

Tabel 2 Peluang dan Tantangan Muatan Lokal Batik

\begin{tabular}{l|l|l|l} 
No & \multicolumn{1}{|c|}{$\begin{array}{c}\text { Potensi } \\
\text { Daerah }\end{array}$} & \multicolumn{1}{|c}{ Peluang } & \multicolumn{1}{|c}{ Tantangan } \\
\hline 1 & $\begin{array}{l}\text { Sumberdaya } \\
\text { manusia }\end{array}$ & SDM yang terampil & $\begin{array}{l}\text { Ketrampilan batik tidak hanya } \\
\text { dimiliki orang pekalongan }\end{array}$ \\
\hline 2 & $\begin{array}{l}\text { Lokasi } \\
\text { geografis }\end{array}$ & $\begin{array}{l}\text { Pekalongan sebagai kota batik } \\
\text { dan dinobatkan sebagai the } \\
\text { world creative city of batik }\end{array}$ & $\begin{array}{l}\text { Pekalongan bukan satu-satunya } \\
\text { kota penghasil batik }\end{array}$ \\
\hline 3 & Budaya & $\begin{array}{l}\text { Batik menjadi warisan budaya } \\
\text { yang sudah bergeser menjadi } \\
\text { salah satu mode busana di } \\
\text { Indonesia }\end{array}$ & $\begin{array}{l}\text { Trend busana batik juga menjadi } \\
\text { ciri dari kota lain }\end{array}$ \\
\hline 4 & Historis & $\begin{array}{l}\text { Pekalongan menjadi akar asal } \\
\text { muasal batik populer bercorak } \\
\text { pesisiran yang mudah diterima } \\
\text { semua kalangan }\end{array}$ & $\begin{array}{l}\text { Batik dari ciri pedalaman juga } \\
\text { diterima di masyarakat }\end{array}$ \\
\hline 5 & Ekonomi & $\begin{array}{l}\text { Batik sudah menjadi tren } \\
\text { ekonomi }\end{array}$ & $\begin{array}{l}\text { Banyak batik impor baik legal } \\
\text { maupun ilegal yang membanjiri } \\
\text { pasar dalam negeri }\end{array}$ \\
\hline
\end{tabular}


Ditinjau dari segi sumber daya manusia, letak geografis, budaya, historis, dan ekonomi, muatan lokal Batik sangat perlu untuk diterapkan pada siswa tuna rungu wicara. Siswa tuna rungu wicara memiliki keterbatasan dalam berkomunikasi, namun mereka masih dapat dikembangkan dari segi kemandiriannya. Muatan lokal batik akan sangat bermanfaat bagi mereka pada saat mereka lulus. Selain itu, muatan lokal batik akan bermanfaat bagi siswa baik dari segi sikap, pengetahuan, maupun ketrampilan. Berikut ini adalah standard kompetensi lulusan yang diharapkan dari penerpan muatan lokal batik.

Tabel 3 Standar Kompetensi Lulusan

\begin{tabular}{l|l}
\multicolumn{1}{c|}{ Komponen } & \multicolumn{1}{c}{ Deskripsi Kompetensi } \\
\hline Sikap & $\begin{array}{l}\text { Menghayati dan mengamalkan sikap sosial seperti disiplin, tekun, } \\
\text { mandiri, percaya diri, jujur, dan kerjasama sesuai konteks dan } \\
\text { konten belajar maupun pembelajaran }\end{array}$ \\
\hline Pengetahuan & $\begin{array}{l}\text { Mengetahui, memahami, dan menerapkan tata cara pembuatan batik } \\
\text { secara faktual, konseptual, dan prosedural sesuai konteks dan } \\
\text { kebutuhan peserta didik }\end{array}$ \\
\hline Ketrampilan & $\begin{array}{l}\text { Mampu menalar, mengolah, dan menyaji baik secara abstrak dan } \\
\text { konkret tata cara pembuatan batik sesuai konteks dan kebutuhan } \\
\text { peserta didik }\end{array}$
\end{tabular}

Siswa tuna rungu wicara memiliki kecerdasan yang masih normal, mereka hanya memiliki ketidakmampuan dalam mendengar dan berbicara. Dengan pertimbangan tersebut, siswa tuna rungu wicara masih dapat dikembangkan dari sisi sikap, pengetahuan dan keterampilan.

\section{SIMPULAN}

SMALB PRI menerapkan muatan lokal Bahasa Jawa pada siswa tuna rungu wicara. Pada proses pembelajaran, guru menghadapi beberapa permasalahan, yaitu: tidak tersedianya buku ajar Bahasa Jawa khusu untuk siswa tuna grahita, keterbatasan media pembelajaran, keterbatasan pencapaian kemampuan dalam pengucapan kosa kata Bahasa Jawa. Selanjutnya peneliti menawarkan rekomendasi kepada kepala sekolah untuk menerapkan muatan lokal Batik yang sesuai dengan kearifan lokal Kota Pekalonga. Namun, untuk realisainya pihak sekolah memerlukan dukungan dari pemerintah daerah, dinas pendidikan, dan komite sekolah. Dukungan tersebut dapat berupa penyediaan laboratorium batik dan perlatan, serta guru khusus yang meguasai Batik.

\section{DAFTAR PUSTAKA}

Bungin, Burhan . 2007. Penelitian Kualitatif. Jakarta: Prenada Media Group.

Dakir. 2004. Perencanaan dan pengembangan kurikulum. Jakarta: Rineka Cipta.

Jannah, Ana Miftakhul, S. Rilla Kartika. 2014. Konsep Anak Berkebutuhan Khusus:

Pengertian Tuna Rungu Wicara. Program Studi Ilmu Keperawatan. Universitas

Jember. Diakses dari

http://www.academia.edu/8962946/Pengertian_Tuna_Rungu_Wicara

Puskur Balitbang. 2002. Kurikulum berbasis kompetensi. Jakarta: Depdiknas

Pusat Kurikulum. 2007. Model dan Contoh Muatan Lokal Pendidikan Dasar dan Menengah

(SD/MI/ SDLB, SMP/MTs/SMPLB, SMA/MA/SMK/SMALB. Badan penelitian dan Pengembangan Pendidikan Nasional. Departemen Pendidkan Nasional. Jakarta.

Tim FIP UPI. 2007. Ilmu Aplikasi Pendidikan. Jakarta: Imtima. 
Sadjaah, Edja. 2005. Pendidikan Bahasa bagi Anak Gangguan Pendengaran dalam Keluarga. Jakarta: Depdiknas Dirjen. Pend. Tinggi Direktorat Pembinaan Pend. Tenaga Kependidikan dan Ketenagaan Perguruan Tinggi.

Yusuf, Muri. 2014. Metode Penelitian Kuantitatif, Kualitatif \& Penelitian Gabungan. Jakarta. Prenadamedia. 